\title{
Antropología, memoria e historia
}

\author{
Anthropology, Memory and History
}

\author{
Alban Bensa \\ INSTITUT DE RECHERCHE INTERDISCIPLINAIRE SUR LES ENJEUX SOCIAUX-ÉCOLE \\ DES HAUTES ÉTUDES EN SCIENCES SOCIALES, alban.bensa@ehess.fr
}

Este texto retoma y prolonga las propuestas metodológicas y teóricas que desarrollé en dos libros, Después de Lévi-Strauss y El fin del exotismo, recientemente publicados en español. ${ }^{1}$

PaLABRAS ClaVE: antropología, historia, memoria.

This text takes up and extends the methodological and theoretical proposals that I developed in two books Después de Lévi-Strauss (After Levi-Strauss) and El fin del exotismo (The End of Exoticism) - both recently published in Spanish.

KEYwORDs: anthropología, history, memory.

P

ara la historia, los archivos; para la antropología, el trabajo de campo. Esta distinción no es esencial. Los antropólogos, especialmente, cuando toman en cuenta el fenómeno de la colonización, las memorias locales o los meandros de la política, revisan los documentos escritos. Desde Michelet que entrevistó a los últimos testigos de la revolución francesa hasta las investigaciones recientes sobre la Shoah, los historiadores saben interrogar a sus contemporáneos. Los oficios divergen sobre otro asunto, el de la interpretación. Ciertamente, los fenómenos sociales son todos históricos, pero pueden alimentar razonamientos diferentes.

La divergencia fundamental entre la historia y la antropología proviene del lugar muy distinto que las dos disciplinas le conceden

${ }^{1}$ Alban Bensa, Después de Lévi-Strauss. Por una antropología de escala humana. Una conversación con Bertrand Richard (México: Fondo de Cultura Económica, 2015); y El fin del exotismo. Ensayos de antropología crítica, trad. Daniel Rudy Hiller (Zamora: El Colegio de Michoacán, Secretaría de Cultura, 2016). 
a la temporalidad. Para la historia queda claro que el tiempo es su materia prima. Las acciones se inscriben en el tiempo, modifican las cosas tanto como las repiten. La idea de la sucesión es esencial, aunque es necesario recurrir a un "haz de causas" para dar cuenta de un fenómeno, como nos invitó a hacerlo Marc Bloch. ${ }^{2}$ Para el antropólogo, si se descuida, el tiempo pasa a un segundo plano, y se procede a dar cuenta de los fenómenos de manera sincrónica, a partir de una concepción puramente espacial, como lo ha mostrado Johannes Fabian. ${ }^{3}$

En cambio, la mayoría de los historiadores reflexionan a partir de coyunturas que reconstruyen. Como bien lo señala Jean-Louis Fabiani, "su oficio es sacar a la luz la irreductible singularidad de los contextos de enunciación". ${ }^{4}$ Sus análisis sólo serán capaces de ampliar la mirada, si no se alejan demasiado de las situaciones descritas. Las categorías a las que recurren nunca están desligadas de las de los propios actores sociales y se confrontan con estas últimas en situaciones claramente ubicadas en el espacio y en el tiempo.

La antropología, por su parte, pretende ser mucho más ambiciosa cuando utiliza la singularidad de los fenómenos históricos y, por ende, sociales como punto de partida para elaborar ideas más generales. Al proponer esquemas que organizarían toda práctica humana, al buscar principios a partir de los cuales se podría encontrar "el fundamento de las sociedades humanas" (lo dicen sin ironía alguna), esta disciplina se eleva de las cosas vistas y escuchadas para integrarlas en lógicas más abarcadoras sobre el sexo, sobre las formas de intercambio y de poder, y sobre lo sagrado.

La noción de "mentalidad", hermana de las de conciencia y representación colectivas, entronizadas por Durkheim y Mauss, es la que marca la diferencia esencial entre las dos disciplinas. La encontramos en el corazón de la antropología histórica de la década de

${ }^{2}$ Marc Bloch, Apologie pour l'histoire ou Métier d'historien, cap. v (París: Armand Colin, 1993), 188.

${ }^{3}$ Johannes Fabian, Time and other. How anthropology makes its object (Nueva York: Columbia University Press, 1983).

${ }^{4}$ Jean-Louis Fabiani, "La généralisation dans les sciences historiques. Obstacle épistémologique ou ambition légitime?", Annales. Histoire, Sciences Sociales 62(1) (enero-febrero 2007): 22. 
1960, pero, por influencia de Claude Lévi-Strauss, se le denominó "pensamiento salvaje" o "pensamiento mítico" y se le dotó de una racionalidad escondida.

El análisis estructural logra circunscribir mejor su objeto cuando excluye de sus procedimientos fundamentales de interpretación cualquier causalidad extrínseca. El examen de los constreñimientos externos no es dejado de lado, pero se reduce a buscar las modalidades en las que el mito se engrana con las infraestructuras y la historia. Sin que las leyes que gobiernan el espíritu sean traicionadas o pierdan su independencia, el pensamiento mítico se modifica, se bifurca y se ajusta a las presiones que ejercen sobre éste, desde el exterior, el medio natural, técnico o histórico. Queda claro que esta perspectiva relega la historia a ser tan sólo el trasfondo de las preocupaciones de los antropólogos que están obsesionados por la búsqueda de permanencias, que estarían más allá de las contingencias y que alcanzarían niveles más profundos de significado.

Así, la historia se desarrollaría en un segundo plano sin afectar los bloques de piedra y otros materiales incorruptibles - pero inconscientes- que estructurarían la vida social pasare lo que pasare. Llama la atención el hecho de que el preámbulo de todos los estudios antropológicos que intentan colocarse por encima del encadenamiento histórico de las circunstancias consiste en barrer los escombros de la historia. Así por ejemplo, Philippe Descola reanuda con esta postura metodológica, insistiendo de entrada en la necesidad de un planteamiento totalmente sincrónico: "en contra del historicismo y de su fe ingenua en la explicación a través de las causas anteriores, hay que reafirmar fuertemente que sólo el conocimiento de la estructura de un fenómeno permite interrogarse de manera pertinente sobre sus orígenes". ${ }^{5}$ Así, pues, para estos antropólogos, resulta indispensable que la coyuntura y el acontecimiento queden reducidos a ser tan sólo la espuma de las olas, el efímero resultado de fuerzas más duraderas y profundas para que el determinismo de los modos de pensamiento, de los sistemas culturales y las reglas universales de los intercambios o, en última instancia, de la economía resulte verosímil.

${ }^{5}$ Philippe Descola, Par-delà nature et culture (París: Gallimard, 2006), 13. 
Mientras la antropología se limite a las esferas genéricas de las estructuras del espíritu humano o al origen lógico de las sociedades, no podrá arrojar una luz convincente sobre los hechos históricos concretos. En cambio, se da los medios para hacerlo cuando descifra los sistemas de relación concretos y, todavía más, cuando el trabajo de campo y de archivo se complementan para alcanzar niveles más finos de la realidad.

La voluntad de varias corrientes antropológicas de acercarse a las ciencias históricas ha resultado un remedio eficaz en contra de la antropología formalista. Por una parte, el difusionismo marcó a la antropología en sus inicios al introducir una reflexión sobre la historia de los contactos culturales. Por otra parte, algunos antropólogos como Max Gluckman, Evans-Pritchard (al final de su carrera) y después George Balandier y Jack Goody reaccionaron rápidamente en contra de la ahistoricidad de las perspectivas funcionalistas y estructuralistas. Este interés por la temporalidad, más que por la estructura, va a encontrar en la propia disciplina histórica una nueva juventud y una ocasión para pensar las relaciones entre la antropología y la historia a partir de la década de 1970.

Con el auge de la microhistoria, las preguntas sobre las relaciones entre los distintos tipos de temporalidad conducen a revalorizar el acontecimiento y el sujeto. En efecto, Carlo Ginzburg se apoya en una reflexión crítica a partir de un tipo de documentos muy circunstanciales -los procesos inquisitoriales- para poner en duda las generalizaciones que había acuñado la historia en la larga duración. A partir de situaciones fechadas con precisión y de actores sociales claramente identificados que dialogan y debaten, la microhistoria se acerca a la sociología interaccionista y a la antropología del cambio social para poner en evidencia los marcos de las experiencias, concepto que no le debe gran cosa a la categoría bastante inmovilista de mentalidad y que está más cerca de una concepción muy dinámica de las relaciones sociales y de la cultura, entendida, como dice Ginzburg, como una "jaula flexible". ${ }^{6}$

${ }^{6}$ Carlo Ginzburg, El queso y los gusanos. El cosmos según un molinero del siglo XVI (Barcelona: Muchnik Editores, 1986), 22. 
Por lo tanto, el trabajo del historiador, al igual que el del etnógrafo, consiste en describir un campo de lucha entre concepciones diversas defendidas por sujetos, cuyos destinos no están decididos de antemano, sino que se despliegan para cada uno según su propia singularidad. Los microhistoriadores, atentos a la temporalidad de corta duración que los mismos sujetos deben de aprehender, recurren a la biografía y a la noción de estrategia para dar cuenta del encadenamiento de hechos y de gestos de cada uno de ellos. La homología entre la etnografía y la microhistoria, que deben enfrentarse con la irreductibilidad de los hechos sociales, sólo fue aceptada por la antropología cuando ésta dejó de pensar que las singularidades históricas no eran tan sólo resultado de estructuras sepultadas bajo las cenizas de los hechos.

En cambio, cuando la antropología se esfuerza por poner en evidencia las situaciones históricas particulares de las personas, entonces revela las razones prácticas y concretas arraigadas en temporalidades precisas y cambiantes. Eso es lo que he pretendido hacer en un libro que se publicó hace poco tiempo, que está centrado en el compromiso de hombres y mujeres perfectamente identificados con la rememoración de su pasado colonial. ${ }^{7}$ Los relatos orales y escritos elaborados a lo largo de un siglo no remiten a una "cultura" nativa de Oceanía, ni siquiera influida por la francesa, sino al uso político del pasado en diferentes periodos de la historia contemporánea de la Nueva Caledonia, pequeño archipiélago francés en el Pacífico Sur.

Quisiera presentar aquí de manera sucinta este caso para darle cuerpo a mis propuestas teóricas.

La guerra que hizo estragos en Europa y en parte de Asia entre agosto de 1914 y noviembre de 1918 abrió nuevas oportunidades. En distintos lugares del planeta, a veces muy alejados de los frentes de batalla en Francia, varias poblaciones maltratadas por el colonialismo buscaron aprovecharse de la situación. Por medio de estos subversivos esfuerzos, los colonizados buscaron recordarles a las potencias colonizadoras que, aunque habían sido conquistados, su país

${ }^{7}$ Alban Bensa, Antoine Goromido y Adrian Muckle, Les Sanglots de l'aigle pêcheur. Nouvelle-Calédonie: la Guerre kanak de 1917 (Tolosa: Anacharsis, 2015). 
seguía perteneciéndoles. Por lo tanto, hay que entender que esos esfuerzos no eran algo que sucedía en los márgenes del imperio, sino que eran focos de rebelión que buscaban restablecer un orden mundial que no fuera exclusivamente eurocéntrico. La Primera Guerra Mundial era el momento adecuado para intentarlo.

En África Occidental, en Argelia, en Marruecos, en Asia, Francia tuvo que enfrentarse en 1917 con movimientos indígenas que se oponían a su dominio. Ese mismo año, las tensiones con las poblaciones autóctonas se exacerbaron cuando París exigió que le enviaran soldados de Nueva Caledonia. ${ }^{8}$ Ahora esbozaremos rápidamente cómo reaccionaron ante esta demanda los primeros pobladores de este archipiélago, los kanak.

Hace unos 10,000 años, poblaciones de lenguas austronesias salidas del sureste de Asia se instalaron en un arco que se extiende desde Madagascar hasta la Isla de Pascua, pasando por Indonesia y las costas de Papúa Nueva Guinea. Como parte de esa migración, hace 4,000 ańos agricultores y pescadores arraigaron en varias islas de lo que ahora es Nueva Caledonia y desarrollaron una civilización original y diversa. ${ }^{9}$ En 1774, el capitán James Cook (1728-1779) desembarcó en lo que denominaría Nueva Caledonia. Francia, a instancias de la Iglesia católica, que buscaba contrarrestar la expansión de los protestantes angloparlantes en el Pacífico, se apropió de Nueva Caledonia el 24 de septiembre de 1853 para hacer de ésta una colonia que empezó a poblar con presos. ${ }^{10}$

Los pobladores autóctonos -a los que se les llamó "kanak" (término hawaiano que significa "hombre")- fueron despojados de las mejores tierras y se enfrentaron a la potencia colonizadora en varias ocasiones. Dos episodios de esta resistencia tuvieron una amplitud considerable: el primero tuvo lugar en 1878, año en el que se produ-

${ }^{8}$ Adrian Muckle, Specters of Violence in a Colonial Context: New Caledonia, 1917 (Honolulú: University of Hawaï Press, 2012).

${ }^{9}$ Véase mapa 1. Nueva Caledonia.

${ }^{10}$ Isabelle Merle, Expériences coloniales: la Nouvelle-Calédonie (1853-1920) (París: Belin, 1995); y Louis-José Barbançon, L'archipel des forçats: histoire du bagne de NouvelleCalédonie, 1863-1931 (Villeneuve-d'Ascq: Presses Universitaires du Septentrion, "Histoire et civilisations", 2003). 
Mapa I. Nueva Caledonia

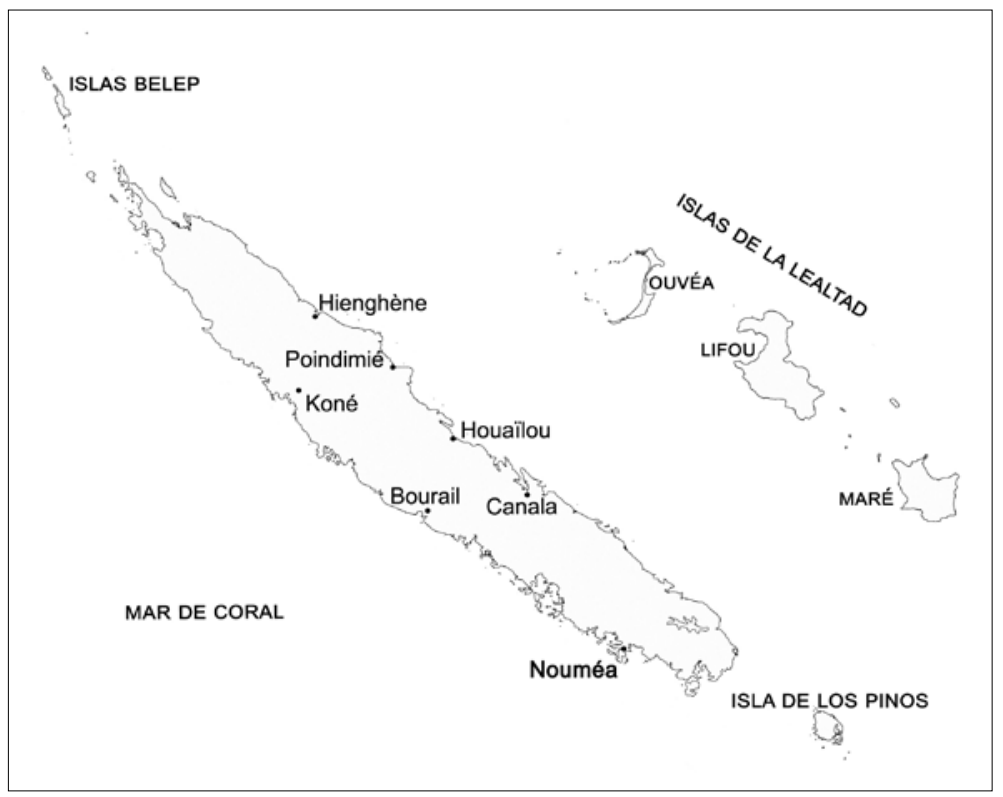

jo un gran levantamiento, cuya represión provocó la expulsión de los kanak de miles de hectáreas de tierra; ${ }^{11}$ el segundo se desarrolló en 1917 para protestar por la leva de soldados que se enviaron al frente durante la Primera Guerra Mundial. En efecto, Francia exigió en 1915 que sus colonias enviaran "voluntarios" para combatir en Europa. ${ }^{12}$ Los kanak oscilaron varias veces entre 1914 y 1917 entre las dos posibilidades que se les presentaban: resignarse a ir a luchar en las trincheras o rebelarse en contra de los administradores franceses. Así, mientras unos partían a Europa a combatir en el frente,

${ }^{11}$ Roselène Dousset-Leenhardt, Colonialisme et contradiction. Nouvelle-Calédonie, 1878-1978. Les causes de l'insurrection de 1878 (París: L'Harmattan, 1978); Alain Saussol, L'Héritage: essai sur le problème foncier mélanésien en Nouvelle-Calédonie (París: Musée de l'Homme, 1979); y Michel Millet, 1878: carnets de campagne en Nouvelle-Calédonie, precedido de La guerre d'Atä̈: récit kanak [de Téâ Henri Wênêmuu, traducido del paicî] (Tolosa: Anacharsis, 2004).

${ }^{12}$ Sylvette Boubin-Boyer, ed., Révoltes, conflits et guerres mondiales en Nouvelle-Calédonie et dans sa région, 2 vols., París: L'Harmattan, 2008). 
otros, a veces sus parientes, atacaban a los colonos y a los agentes reclutadores encargados de la represión.

Así, en 1917, los kanak se enfrentaron a una nueva situación geopolítica. Por primera vez, la república francesa se veía involucrada en un conflicto mundial que la debilitaba. Por primera vez, cualquier acontecimiento acaecido en la Primera Guerra Mundial llegaba a los oídos de todos, incluso en las tribus más alejadas. Las noticias circulaban a toda velocidad en vista de que muchos kanak sabían leer y escribir. Otros trabajaban como sirvientes de los colonos o para la administración pública y penitenciaria en Numea. También los trabajadores contratados en las Nuevas Hébridas, en Indochina, en las islas holandesas y en Tahití transmitían la información que habían recogido en distintos lugares del Pacífico asiático.

Estas experiencias alimentaron la reflexión de los kanak sobre Nueva Caledonia y sobre el mundo en que vivían. Éste había sufrido un gran desgaste: la caída demográfica de la población autóctona de Nueva Caledonia y de todas las islas del Pacífico había sido muy rápida en el siglo XIX, a pesar de que se haya exagerado en algo su magnitud. ${ }^{13}$ Probablemente, en el momento del contacto con los europeos, había 100,000 kanak. Para el momento del censo de 1911, sólo quedaban 30,000 personas. Aunque más de mil kanak fueron a luchar en las trincheras y la mayoría de los pobladores autóctonos había aceptado el orden político cristiano y habían aprendido a hablar en francés y a leer y escribir, nunca se les agradeció por ello. La memoria de los kanak de 1917 y de sus descendientes quedó marcada por esta falta de reconocimiento.

La guerra de 1914 en Francia y la de 1917 en Nueva Caledonia transformaron los lazos entre la metrópoli y los indígenas de Oceanía, al expandir su conocimiento del mundo y sus formas de expresión. El sentimiento que se impuso entre ellos fue la desilusión.

La resistencia se concentró, entonces, discretamente en un espacio narrativo muy específico. Nuevas generaciones de eruditos locales se pusieron a trabajar para conservar la historia de sus clanes, de

${ }^{13}$ Dorothy Shineberg, They Came for Sandalwood. A Study of the Sandalwood Trade in the South-West Pacific, 1830-1865 (Carlton: Melbourne University Press, 1968). 
sus migraciones, de las jefaturas, de sus alianzas y de sus guerras, todo ello en sus lenguas, y a menudo recurriendo a la escritura. Desplegaron en forma continua enunciados que ligaban el pasado al presente en ambos sentidos hasta construir los fundamentos de una memoria colectiva. Los kanak recurrieron a la formalización de sus recuerdos por medio de obras que durante mucho tiempo quedaron enterradas en la oralidad local y en cuadernos guardados en cajones de sus chozas, pero que tenían la finalidad de que su civilización igual de legítima que cualquier otra- lograra sobrevivir.

¿De qué manera se relacionan los historiadores de las tribus con el pasado? Gracias a las experiencias trasmitidas de generación en generación, herederos de las formas de expresión kanak y alfabetizados por los curas misioneros, los guardianes de la memoria nos invitan a no aceptar las afirmaciones de los universitarios europeos como la verdad absoluta, sino a poner dichas afirmaciones en el contexto de su época y, en especial, en el contexto de la violencia colonial, que buscaba silenciar e invisibilizar a los indígenas. Esta nueva forma de ver las cosas ha sido obra de una corriente historiográfica que busca provincializar Europa, a partir de la historia de la India, ${ }^{14}$ de los indoamericanos, ${ }^{15}$ de los negros de Surinam ${ }^{16}$ y de los polinesios, entre otros. Como lo ha mostrado Romain Bertrand, haciendo referencia a Indonesia, "Java no fue el recipiente pasivo de la modernidad europea, por el contrario era la guardiana de otras posibilidades históricas" ${ }^{17} \mathrm{El}$ recurso a la memoria kanak, entonces, nos hablará de la guerra de 1917, invitándonos a tomar en cuenta los secretos coloniales más profundos de su relación con el resto del mundo.

Su manera de narrar el pasado fundamenta otra perspectiva histórica que contradice el monopolio del discurso histórico que buscan implantar los no kanak. Esto plantea la pregunta de la

${ }^{14}$ Dipesh Chakrabarty, Al margen de Europa. Pensamiento poscolonial y diferencia histórica (Barcelona: Tusquets Editores, 2008).

${ }^{15}$ Nathan Wachtel, La Vision des vaincus: les Indiens du Pérou devant la conquête espagnole, 1530-1570 (París: Gallimard, 1971).

${ }^{16}$ Richard Price, First-Time: The Historical Vision of an Afro-American People (Baltimore: Johns Hopkins University Press, 1983).

${ }^{17}$ Romain Bertrand, L'Histoire à parts égales: Récits d'une rencontre, Orient-Occident (XVIe-XVIIe siècle) (París: Éditions du Seuil, 2011), 22. 
compatibilidad de los puntos de vista sobre lo que sucedió en el pasado. ¿Podemos suponer que todas las narrativas históricas pueden fundirse en una historia "común" o "total", por medio de la cual los enfrentamientos desatados por la colonización desaparecerían? ¡Vana ilusión! No sólo existen distintas perspectivas históricas del pasado colonial, sino que éstas se seguirán expresando con firmeza. De hecho, hasta ahora la historia de Kanaky-Nueva Caledonia nunca se ha esforzado por tratar en forma "igualitaria" las dos versiones, sino que, por el contrario, ha sido un monopolio de los europeos y de los académicos. El tiempo ha llegado de construir una historia equitativa, es decir, una historia que le reconozca a cada uno lo que le corresponde y así restablezca el equilibrio.

Los relatos orales y escritos de los kanak de la guerra de 1917 que grabamos y recopilamos, y sobre los cuales hemos trabajado, vienen de lejos. Por ello, no es una cuestión secundaria el recordar que estos relatos fueron obra de memorialistas kanak sobrevivientes que buscaron cerrar las heridas abiertas en el cuerpo social por la colonización. Para evitar que una vez más miles de referencias y de saberes desaparecieran para siempre -como había sucedido a lo largo del siglo XIX, cuando los que los poseían murieron en forma masiva- los sobrevivientes se volcaron para que sus recuerdos y sus costumbres no cayeran en el olvido y se conservaran a cualquier costo hasta que llegaran tiempos mejores.

A los antiguos soportes de la memoria -la lectura de paisajes socializados o el arte de la oratoria que, al formalizar la expresión de los recuerdos, permite que los saberes pasen de una generación a otra para ser constantemente reinterpretados-, se ańadieron las técnicas escriturales, que fueron tomadas y posteriormente desarrolladas desde el principio de la Colonia. Los grabados en bambú y la apropiación de la escritura alfabética, introducida por los blancos, fueron asociados por los kanak a la transmisión oral, para finalmente reflexionar sobre su historia por medio de un impresionante palimpsesto pronunciado, escrito, repetido, vuelto a copiar, aumentado, releído y reinterpretado sin descanso desde 1853 hasta nuestros días. Su fabricación y su mantenimiento ha sido obra de un estrato social cada vez más amplio de letrados dedicados a volver a 
poner a flote la civilización kanak, que parecía haber naufragado a principios del siglo xx. Estos hombres y mujeres, como respuesta a la marginación que sufrieron, lograron restaurar un medio cultural y social original y eficaz.

Desde los primeros contactos con los europeos, los kanak emprendieron un trabajo de memorización inmediata. Esta labor era de una urgente necesidad, dado que como su sociedad estaba fragmentada, ello requería un conocimiento preciso de la historia de cada uno de los segmentos que componían su espacio político: las unidades domésticas que se ligaban entre sí por medio de acuerdos entre parientes, mientras que los grupos residenciales se ampliaban o se disolvían por medio de acuerdos, de partidas, de refundaciones de las que había que conservar el recuerdo para mantener o reconstruir el estatuto de cada uno. La construcción de genealogías y de itinerarios para quedar ligado a una tierra de origen y las elaboraciones de relatos que legitimaban la posición social del narrador constituyeron, junto con las poesías recitadas o cantadas, el corazón de los saberes inventariados. Como bien dijo Víctor Hugo, "a los vencidos, les es permitido sońar". ${ }^{18}$ Sin lugar a dudas, los kanak lograron al final permanecer como población y como civilización gracias a que recurrieron a la fuerza del recuerdo y a las artes de la memoria para encontrar los medios intelectuales y narrativos para sobrevivir.

De esta forma, los kanak se dieron a la tarea de recordar los acontecimientos que organizaron o trastornaron su vida colectiva. Las numerosas rupturas de inteligibilidad los invitaron a volver a conquistar el sentido de la vida social, de lo que dan testimonio diversas obras plásticas y narrativas que perduran en el tiempo. ${ }^{19}$ Este esfuerzo por dejar testimonios y la articulación de las huellas del pasado con el presente requirieron de técnicas y soportes diversos, como el bambú grabado, las artes oratorias o la escritura en lenguas vernáculas.

Mucho antes de la colonización, los kanak habían grabado figuras en la piedra. Muchos petroglifos dan fe de un trabajo de memoriza-

${ }^{18}$ Víctor Hugo, "Préface", Les Chansons des rues et des bois (Varias ediciones). (2002).

${ }^{19}$ Alban Bensa y Eric Fassin, "Les sciences sociales face à l'événement", Terrain (38) 
ción gráfica que se relaciona con los mitos de origen, con situaciones particulares o con acontecimientos diversos (el número de esposas de un jefe, las ceremonias, las historias de los clanes, etcétera).

Los bambúes grabados muestran, en el caso de los más antiguos, formas geométricas, que han sido interpretadas de muchas maneras. Pero desde la llegada de los europeos, los dibujos figurativos se vuelven dominantes. Hacen referencia tanto a la vida social kanak como a la presencia europea. La transmisión de los hechos más relevantes se apoyó en este lenguaje pictórico original, que conoció un gran auge entre 1840 y 1920. Sin pretender ver en ello una causalidad mecánica, podemos anotar que, cuando la escritura arraiga en el mundo kanak, se dejan de grabar bambúes. Este abandono es tal vez también el signo del paso de un arte gráfico popular a formas escritas de la narrativa. De hecho, el bambú grabado era ya uno de sus soportes. Los kanak tenían la costumbre de conservar los acontecimientos (ceremonias importantes, migraciones de las poblaciones, guerras) en unas composiciones llamadas en la lengua paicî, ténô.

Ténô significa rumor, celebridad, palabra pública que difunde las noticias. Esta forma oral abunda y, hasta hace 30 años, se les aprendía de memoria y se les recitaba a menudo. El ténô remite en forma alegórica, condensada e ilustrativa a episodios particulares de la vida social y de la historia colectiva: guerras, alianzas, historias familiares. Este género narrativo muy estereotipado es una creación en versos de ocho pies (en principio), recitados por estrofas, dichas de un jalón. El corpus muy variado de los ténô permite acceder a la historia local y también a escenas de la vida cotidiana de los kanak (elección del cónyuge, fiestas), recurriendo a un vocabulario más escogido que el de la lengua de todos los días. Estos diferentes tipos de expresión formalizada transmiten por lo tanto saberes históricos. Cada uno de éstos le aporta a la historia que narra un matiz y, al estilizarla, la eleva más allá de su puro contenido fáctico.

El ténô -este género fundamental de las formas de expresión paicî- existía, sin duda alguna, antes de la colonización. Pero, al igual que en el caso de los bambús grabados, todas las poesías de las que disponemos se refieren a acontecimientos que tuvieron lugar en 
los siglos XIX y XX, aunque ciertos pasajes - desde unos cuantos versos hasta varias estrofas- provienen de obras anteriores, son ecos de hechos históricos más antiguos y de otras guerras, cuyos recuerdos versificados fueron en ocasiones utilizados para evocar conflictos más recientes.

Así, si el grabado en bambú constituyó una reacción gráfica a la brutal llegada de los colonos europeos, los kanak, al mismo tiempo, ampliaron sus posibilidades de expresión al añadir, a la oralidad, la escritura alfabética, herramienta principal de la evangelización del Pacífico. Los protestantes de inspiración calvinista de la London Missionnary School basaron su proselitismo en la traducción de la Biblia a las lenguas locales y en la formación de un clero indígena.

En Nueva Caledonia, autores claramente individualizados, actores sociales o testigos directos de las guerras, de los desplazamientos de población y de las múltiples desgracias padecidas antes y después de la proclamación del Estatuto Indígena (Code de l'Indigénat) compusieron relatos orales $y$, también, -algo que se olvida a menudotextos escritos. Estos kanak vieron en este nuevo medio la manera de perpetuar el recuerdo de los espacios que tuvieron que abandonar y la memoria de la agitada historia de sus clanes y jefaturas. La apropiación de la escritura resultó para los colonizados un acto político de gran importancia. Al adueñarse de este nuevo saber, los primeros escribas melanesios se apoderaron, en provecho propio, de una de las principales fuerzas de los colonizadores, la de poder comunicarse a distancia y con el futuro. Fue así como se consolidó poco a poco un grupo de letrados, quienes desempeñarán un papel esencial en la historia de Nueva Caledonia.

De generación en generación, se constituyó un estrato de eruditos que dominaban tanto los saberes orales como la escritura. Estas personas, aunque no muy numerosas, fueron poco a poco desempeñando un papel más importante. Las escuelas religiosas y luego públicas, diseñadas en Francia ex profeso para los indígenas, contribuyeron a este auge, que la mayoría de los colonos no habían deseado. Marie Salaün ha mostrado las contradicciones de esta política educativa: "Hay que 'educar al kanak' para que sea capaz de difundir la influencia francesa, teniendo cuidado de no liberarlo de su estatuto de 
subalterno que es el suyo en el marco del Estatuto Indígena”. ${ }^{20}$ Una educación de bajo costo llevada a cabo en condiciones materiales deplorables bastaba para alcanzar ese objetivo.

El dominio de la escritura, que se adquiría en la escuela, servía para anotar los saberes en lenguas vernáculas, poniendo al servicio de los kanak una técnica que en su origen estaba dirigida a consolidar el proyecto colonizador. Al escribir para ellos mismos, los kanak supieron sacar partido de una política menos interesada en su emancipación que en su sujeción. Este giro ejemplar fortaleció la autoridad de estos nuevos personajes en el mundo kanak. El pequeño grupo de kanak que recurrió a la escritura en sus lenguas maternas a finales del siglo xIx fue creciendo a todo lo largo del siglo xx. La formación de este estrato de especialistas de la memoria, en la confluencia de la oralidad y de la escritura, fue una hábil respuesta a la arrogancia colonial.

El drama de 1917 dio lugar a composiciones orales y escritas, probablemente sin precedente alguno, que fueron memorizadas y copiadas durante las décadas siguientes. Con meticulosidad y tenacidad, hombres y mujeres de las dos vertientes de las áreas lingüísticas que participaron en la sublevación las memorizaron y las copiaron repetidas veces, sacando partido de las enseñanzas impartidas en las escuelas religiosas o públicas. La voluntad de los kanak de no dejarse vencer por la adversidad supo aprovecharse, desviándolos en provecho propio, de los aportes de las misiones y de la escuela pública para dar lugar a un contrapoder discreto, pero sólido, que se obtuvo gracias a "una serie de ajustes sociales". ${ }^{21}$ Los hijos y los nietos de los letrados kanak del periodo de entreguerras se volvieron durante las últimas cinco décadas, las personalidades políticas centrales de los partidos que lucharon primero por la autonomía y luego por la independencia.

Durante los 40 ańos (1878-1918) que separan las dos épocas, la expresión oral, escrita y plástica se intensificó, de lo que dan testi-

${ }^{20}$ Marie Salaün, L'école indigène. Nouvelle-Calédonie, 1885-1945 (Rennes: Presses Universitaires de Rennes, 2005), 128.

${ }^{21}$ Eric Soriano, La fin des indigènes en Nouvelle-Calédonie. Le colonial à l'épreuve du politique 1946-1976 (París: Karthala, 2014). 
monio las obras escritas en las décadas de 1880 a 1910 sobre la muerte de los jefes clánicos o de la llegada de la religión. En el momento en que estalló la Primera Guerra Mundial, los kanak disponían de una experiencia narrativa y literaria que con el conflicto en Europa y en Nueva Caledonia se volvió de gran ayuda. Las composiciones, orales y escritas, florecieron en tanto esfuerzos para pensar y transmitir las causas y las consecuencias de esta sublevación que se desarrolló en un contexto muy distinto a la de 1878 .

Una nueva división del espacio supone un nuevo orden del tiempo. La situación colonial y los episodios revolucionarios desgarran las temporalidades. No importa que las explosiones sean endógenas, como las revoluciones, o exógenas, como las conquistas padecidas por los colonizados, las rupturas, las aceleraciones y las bifurcaciones vienen a quebrar los procesos temporales que venían desenvolviéndose. Así, las transformaciones políticas y los desarrollos específicos del Pacífico Sur se vieron interrumpidos por la llegada de europeos en busca de tierras por razones que les eran propias. Éstos arrojaron sobre las sociedades del Pacífico una losa de cemento: la de los estados-nación y su modelo de un poder centralizador, limitado por rígidas fronteras, como lo eran Inglaterra, Francia o Alemania y de sus imperios coloniales. ${ }^{22}$

Se impusieron entonces a los primeros habitantes de las tierras despojadas inéditas experiencias del tiempo y nuevas y restringidas perspectivas sobre las posibilidades de acción, pero sobre las cuales podían reflexionar y actuar. Los kanak tuvieron que darle un nuevo sentido a los acontecimientos, clasificarlos, reorientarlos y encontrar la razón de $\operatorname{ser}^{23}$ del despojo agrario, de las epidemias, de las deportaciones o de las masacres. Ante estos acontecimientos inéditos, las memorias y las esperanzas se exacerbaron y, en todo el Pacífico, aparecieron nuevas formas de periodizar la historia a partir del siglo XIX.

${ }^{22}$ Benoît Antheaume y Joël Bonnemaison, Atlas des îles et États du Pacifique Sud (Montpellier, París: GIP RECLUS, Publisud, 1988).

${ }^{23}$ François Hartog, Regimenes de historicidad. Presentismo y experiencias del tiempo (México: Universidad Iberoamericana, 2007); y Karl Jacobi, Shadows at dawn. A Borderlands Massacre and the Violence of History (Nueva York, Londres: Penguin, 2008). 
La historiografía dominante sobre Nueva Caledonia es toda europea. Sin embargo, los kanak han erigido sus construcciones temporales inéditas para ellos antes de la colonización. Tuvieron que pensar el choque de civilizaciones. Pero la forma segmentada de la sociedad melanesia dio lugar a relatos diferenciados según las localidades y la historia de cada una de éstas.

La violencia militar, la territorial, la económica y la ideológica, por medio del trabajo de menosprecio que muy pronto echaron a andar los misioneros (al oponer sus propias creencias a las de los autóctonos fundadas en el respeto a los antepasados y a la captura de los poderes de éstos), moldearon la memoria de los kanak, siempre encuadrada por la lógica segmentaria y sus miles de nombres propios. La preocupación mayor de los narradores, poetas y otros escultores de la memoria fue pensar la historia a partir de los arcanos del mundo kanak y de sus necesidades. Así lograron capturar los acontecimientos de acuerdo con sus propios esquemas de pensamiento $y$, con ello, contrarrestaron a su manera el apresamiento del tiempo, inseparable del control del espacio, que se produce en toda dominación colonial.

La guerra de 1914 en Francia y la de Nueva Caledonia en 1917 permitieron a los kanak volver a evaluar sus lazos con la metrópoli, al ensanchar el horizonte de su pensamiento y sus formas de expresión. Como podemos ver, no se trató en modo alguno de una forma de repliegue, por el contrario, estamos ante diversos intentos de sacar provecho de la nueva situación.

Los relatos y las poesías épicas dan testimonio de las relaciones de los kanak con el mundo globalizado de la última fase de la Primera Guerra Mundial. Los colonizados se apoderaron de los acontecimientos de aquel entonces para renovar sus creaciones orales y, así, poder afrontarlos intelectualmente y afectivamente. Aunque aparecieron imágenes inéditas, nombres propios o de países que nunca habían sido citados, la forma rítmica siguió siendo la misma, al igual que el cuadro general de referencia: es decir, el mundo kanak con sus prácticas sociales y sus costumbres, siempre renovadas. Los préstamos culturales y la influencia de los nuevos acontecimientos no carcomieron su visión del mundo centrada en lo local y en su histo- 
ria. Si adoptamos el punto de vista de las sociedades que Occidente cree equívocamente englobar, las nociones de pueblos civilizados y pueblos por civilizar se equilibran, cada uno de ellos creyendo poseer la verdad, sin aceptar someter su historiografía a la del otro.

Las relaciones intratemporales entre personas y acontecimientos al interior de un mismo periodo histórico, por muy enlazadas que estén las unas con las otras, están cruzadas por una corriente del tiempo más general que, a partir de un hecho fundador (la vida de Cristo, la Revolución, la colonización, etcétera), enlaza entre sí varias épocas en una lógica común del devenir. Pero la intra e intertemporalidad que los antropólogos e historiadores comparten no llegan a suscitar una reflexión sobre la historia, no sólo como ideología vivida, sino también como fuerza transformadora.

La antropología encuentra en la historia la inteligibilidad de las iniciativas. En el ejemplo que hemos abordado, la expresión oral y escrita no es reducida a una "mentalidad". Las poesías históricas, los relatos, los discursos remiten a creaciones de actores singulares, de letrados comprometidos con un trabajo de rememoración que es también un trabajo político consciente.

La antropología sólo se distingue de la historia por el hecho de que la primera disciplina construye su propia documentación, al mismo tiempo que aprovecha la que utilizan los historiadores. Por último, la antropología hace énfasis, a su vez, en las formas de transmisión y en la intervención de los saberes en la vida social y política.

A fuerzas de subrayar la influencia de la cultura sobre las representaciones históricas, se corre el riesgo de perder de vista que el tiempo -como lo muestra convincentemente Paul Ricoeur-es un "universal englobante". ${ }^{24}$ Es cierto que Cronos puede ser percibido a través de los códigos culturales -no presenta ni la misma imagen ni las misma historia en todas partes-, pero su régimen propio, el de la tragedia del "nunca más", sobrepasa todas las historicidades singulares. Por lo tanto, habría que acompañar el interés que le prestamos a las formas que las sociedades le dan al tiempo, con un examen

${ }^{24}$ Paul Ricoeur, Temps et récit. 1. L'intrigue et le récit historique (París: Éditions du Seuil, 1983). 
más pragmático de los esfuerzos a través de los cuales los hombres actúan astutamente ante su inexorable poderío para encontrar, a pesar de todo, razones para luchar. Sólo entonces la antropología y la historia podrán reconciliarse por completo.

\section{Traducción del francés de Juan Pedro Viqueira}

BiBLIOGRAFÍA

Antheaume, Benoît y Joël Bonnemaison. Atlas des îles et États du Pacifique Sud. Montpellier, París: GIP RECLUS, Publisud, 1988. BARBANÇON, Louis-José. L'archipel des forçats: histoire du bagne de Nouvelle-Calédonie, 1863-1931. Villeneuve-d'Ascq: Presses universitaires du Septentrion, "Histoire et civilisations", 2003.

Bensa, Alban. Después de Lévi-Strauss. Por una antropología de escala humana. Una conversación con Bertrand Richard. México: Fondo de Cultura Económica, 2015.

Bensa, Alban. El fin del exotismo. Ensayos de antropología crítica. Zamora: El Colegio de Michoacán, Secretaría de Cultura, 2016.

Bensa, Alban, Kacué-Yvon Goromido y Adrian Muckle. Les sanglots de l'aigle pêcheur. Nouvelle-Calédonie: la Guerre kanak de 1917. Tolosa: Anacharsis, 2015.

Bensa, Alban y Eric Fassin. "Les sciences sociales face à l'événement". Terrain 38 (2002): 5-20.

BERTRAND, Romain. L'Histoire à parts égales: Récits d'une rencontre, Orient-Occident (XVIe-XVIIe siècle). París: Éditions du Seuil, 2011.

Bloch, Marc. Apologie pour l'histoire ou Métier d'historien. París: Armand Colin, 1993.

Boubin-Boyer, Sylvette, ed. Révoltes, conflits et guerres mondiales en Nouvelle-Calédonie et dans sa région, 2 Vols. París: L'Harmattan, 2008.

Chakrabarty, Dipesh. Al margen de Europa. Pensamiento poscolonialy diferencia histórica. Barcelona: Tusquets Editores, 2008.

Descola, Philippe. Par-delà nature et culture. París: Gallimard, 2006.

Dousset-Leenhardt, Roselène. Colonialisme et contradiction. 
Nouvelle-Calédonie 1878-1978. Les causes de l'insurrection de 1878. París: L'Harmattan, 1978.

Fabian, Johannes. Time and other. How anthropology makes its object. Nueva York: Columbia University Press, 1983.

Fabiani, Jean-Louis. "La généralisation dans les sciences historiques. Obstacle épistémologique ou ambition légitime?". Annales. Histoire, Sciences Sociales 62(1) (enero-febrero 2007): 22.

GinzBurg, Carlo. El queso y los gusanos. El cosmos según un molinero del siglo XVI. Barcelona: Muchnik Editores, 1986.

Hartog, François. Regímenes de historicidad. Presentismo y experiencias del tiempo. México: Universidad Iberoamericana, 2007.

Hugo, Víctor. Les Chansons des rues et des bois. Varias ediciones.

JACOBY, Karl. Shadows at dawn. A Borderlands Massacre and the Violence of History. Nueva York y Londres: Penguin, 2008.

Merle, Isabelle. Expériences coloniales: la Nouvelle-Calédonie (18531920). París: Belin, 1995.

Millet, Michel. 1878: carnets de campagne en Nouvelle-Calédonie, precedido de La guerre d'Ataï: récit kanak [de Téâ Henri WÊNÊMUU, traducido del paicî̀. Tolosa: Anacharsis, 2004.

Muckle Adrian. Specters of Violence in a Colonial Context: New Caledonia, 1917. Honolulú: University of Hawaï Press, 2012.

PRICE, Richard. First-Time: The Historical Vision of an Afro-American People. Baltimore: Johns Hopkins University Press, 1983.

Ricoeur, Paul. Temps et récit. 1. Lintrigue et le récit historique. París: Éditions du Seuil, 1983.

Salaün, Marie. L'école indigène. Nouvelle-Calédonie, 1885-1945. Rennes: Presses Universitaires de Rennes, 2005.

SAussol, Alain. L'Héritage: essai sur le problème foncier mélanésien en Nouvelle-Calédonie. París: Musée de l'Homme, 1979.

Shineberg, Dorothy. They Came for Sandalwood. A Study of the Sandalwood Trade in the South-West Pacific, 1830-1865. Carlton: Melbourne University Press, 1968.

Soriano, Eric. La fin des indigènes en Nouvelle-Calédonie. Le colonial à l'épreuve du politique 1946-1976. París: Karthala, 2014.

WaChtel, Nathan. La Vision des vaincus: les Indiens du Pérou devant la conquête espagnole, 1530-1570. París: Gallimard, 1971. 